\title{
A significant cathodic shift in the onset potential of photoelectrochemical water splitting for hematite nanostructures grown from Fe-Si alloys $\uparrow$
}

Received 30th December 2013 Accepted 19th February 2014

\author{
Lei Wang, ${ }^{a}$ Chong-Yong Lee, ${ }^{a}$ Robin Kirchgeorg, ${ }^{a}$ Helga Hildebrand, ${ }^{a}$ Julian Müller, ${ }^{b}$ \\ Erdmann Spiecker ${ }^{b}$ and Patrik Schmuki*ac
}

DOI: $10.1039 / \mathrm{c} 3 \mathrm{mh} 00173 \mathrm{c}$

rsc.li/materials-horizons

Thermal oxidation of Fe to nanostructured hematite (wires, flakes) is currently widely investigated to produce efficient photoanodes for photoelectrochemical water splitting. The process carried out on pure iron, however, has the key drawback that not only hematite but a layered structure of $\mathrm{Fe}_{2} \mathrm{O}_{3}-\mathrm{Fe}_{3} \mathrm{O}_{4}-\mathrm{FeO}$ is formed where the thick suboxide layer underneath the $\mathrm{Fe}_{2} \mathrm{O}_{3}$ is highly detrimental to the photoresponse. In the present work, we show that suboxide formation can be largely suppressed if hematite nanowires/nanoflakes are thermally grown on Fe-Si alloys. For hematite structures grown on a $\mathrm{Fe}-\mathrm{Si}$ alloy with 5 at\% $\mathrm{Si}$, a photocurrent onset potential as low as $0.6 \mathrm{~V}_{\mathrm{RHE}}$ can be reached (under AM 1.5 illumination and $1 \mathrm{M} \mathrm{KOH}$ ). We believe that the results represent a key finding towards the formation of optimized hematite nanostructures using a thermal oxidation method.

Hematite $\left(\alpha-\mathrm{Fe}_{2} \mathrm{O}_{3}\right)$ has been considered as a promising anode material for photoelectrochemical (PEC) water splitting due to its narrow band gap energy $(\sim 2.2 \mathrm{eV})$, which is suitable for absorption of a large part $(\approx 15 \%)$ of the solar spectrum. ${ }^{1}$ Hematite has an indirect band gap with a comparably low optical absorption coefficient, and therefore an $\alpha-\mathrm{Fe}_{2} \mathrm{O}_{3}$ photoanode should be considerably thick (typically, several $100 \mathrm{~nm}$ ) to fully absorb incident light. However, the material has a poor conductivity and an extremely short hole diffusion length $(\sim 4 \mathrm{~nm})$. To resolve this conflict between short hole diffusion length and low light absorption coefficient, frequently, vertically arranged one-dimensional (1-D) nanostructures such as tubes, wires or rods have been proposed. ${ }^{2}$ In such photoanodes, the

${ }^{a}$ Department of Materials Science and Engineering, WW4-LKO, University of Erlangen-Nuremberg, Martensstr. 7, D-91058 Erlangen, Germany.E-mail: schmuki@ ww. uni-erlangen.de

${ }^{b}$ Department of Materials Science and Engineering, Center for Nanoanalysis and Electron Microscopy (CENEM), University of Erlangen-Nuremberg, Cauerstrasse 6, D-91058 Erlangen, Germany

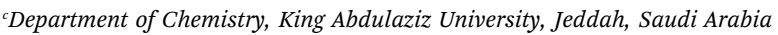

$\dagger$ Electronic supplementary information (ESI) available. See DOI: $10.1039 / \mathrm{c} 3 \mathrm{mh} 00173 \mathrm{c}$ vertical direction serves as the light absorption path while minority carriers can be transported orthogonally without much loss to the electrolyte. ${ }^{3}$

A most simple, cheap, and direct procedure to produce high aspect ratio nanostructures (e.g. 1-D $\alpha-\mathrm{Fe}_{2} \mathrm{O}_{3}$ wires or others) is thermal oxidation of metallic iron. Under specific thermal annealing conditions, spontaneously, oxide whisker (or nanowire) growth can be observed. ${ }^{4}$ Several reports on trials to optimize density and geometry of the grown Fe-oxide nanowires (NWs) or nanoflakes (NFs) exist., ${ }^{4,5}$ Although these structures are very promising in morphology, the actual photocurrents obtained from such nanostructured electrodes are rather poor. ${ }^{5 a, 6,7}$ This is to a large extent due to the formation of thick sub-oxide phases such as magnetite $\left(\mathrm{Fe}_{3} \mathrm{O}_{4}\right)$ underneath the hematite structures. Under many thermal oxidation conditions, a $\mathrm{Fe}_{2} \mathrm{O}_{3}-\mathrm{Fe}_{3} \mathrm{O}_{4}-\mathrm{FeO}$ gradient is formed. The thick $\mathrm{Fe}_{3} \mathrm{O}_{4}-\mathrm{FeO}$ suboxide layers are particularly detrimental to the photoresponse because these phases represent a barrier for charge transfer to the back contact. ${ }^{4}$

In the present paper, we report on an approach to largely suppress the formation of such thick suboxide scales. For this we use, instead of a pure Fe substrate, a Fe-Si alloy (with 5 at $\%$ $\mathrm{Si})$. We find that during the thermal oxidation process, $\mathrm{Si}$ is accumulated as a thin $\mathrm{SiO}_{2}$ film at the metal-oxide interface this provides a highly beneficial protection layer that prevents the growth of a several micrometer thick $\mathrm{Fe}_{3} \mathrm{O}_{4}$ layer underneath the $\alpha-\mathrm{Fe}_{2} \mathrm{O}_{3}$ layer (ESI, Fig. S1 $\dagger$ ). As a result, a considerable cathodic shift of the water-splitting onset potential to 0.6 $\mathrm{V}_{\mathrm{RHE}}$ in $1 \mathrm{M} \mathrm{KOH}$ (under $\mathrm{AM} 1.5,100 \mathrm{~mW} \mathrm{~cm}^{-2}$ ) for a hematite layer formed on a 5 at\% Si alloy can be observed.

Fig. 1a and b show the top surface morphologies of Fe and Fe5Si substrates after the growth of oxide flakes by air annealing at $500{ }^{\circ} \mathrm{C}$ (insets) and after conversion to nanorods in $\mathrm{Ar}$ $\left(600{ }^{\circ} \mathrm{C}\right)$. The conversion of flakes to rods is beneficial as it optimizes geometry and eliminates defects present in the NFs prepared by this method of oxidation..$^{1 c, 4 b}$ In general, for the Si alloy a slightly lower density of NFs and resulting nanorods formed on the substrate than on pure Fe (see Fig. 1a and b and 

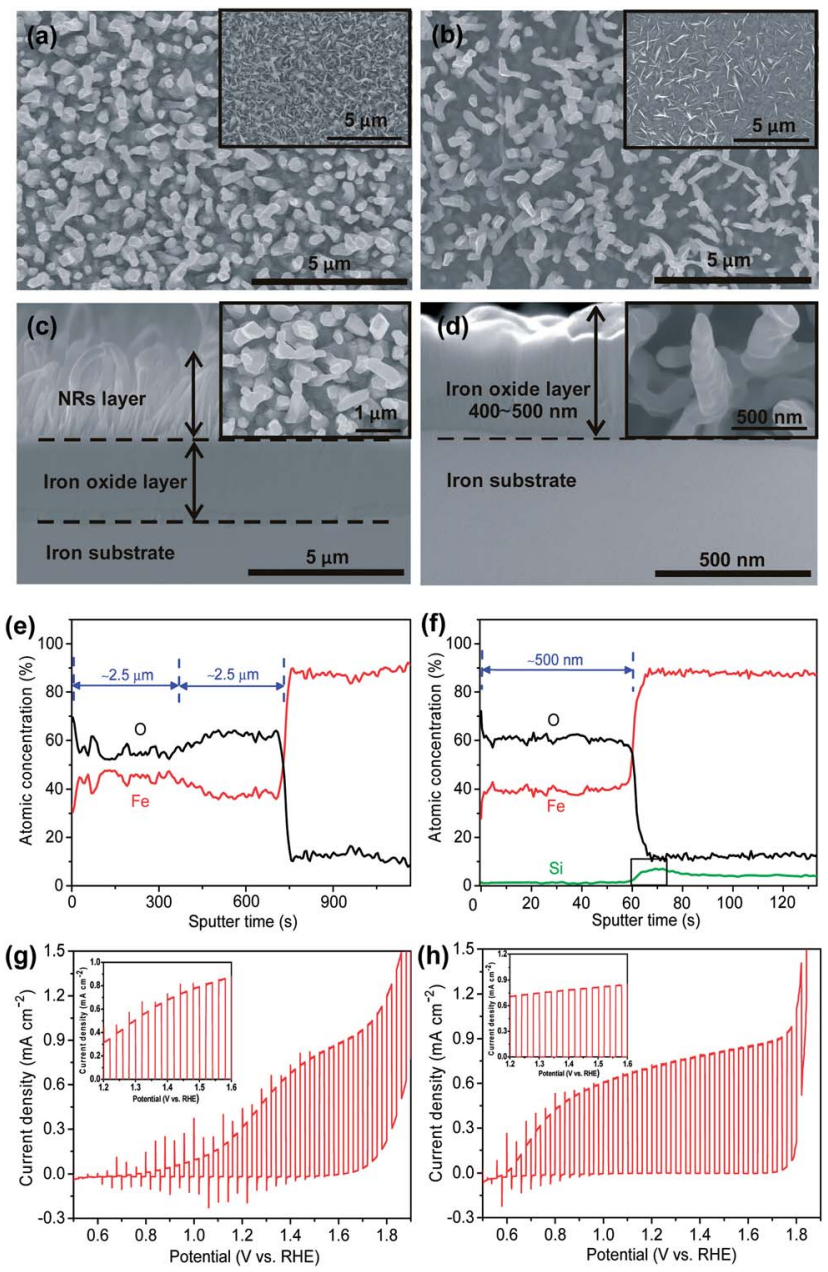

Fig. 1 (a-d) SEM top views and cross-sections of oxide films resulting from ( $a$ and c) Fe and ( $b$ and d) Fe5Si alloy annealed at $500{ }^{\circ} \mathrm{C}$ for $0.5 \mathrm{~h}$ in air $+600{ }^{\circ} \mathrm{C}$ for $1 \mathrm{~h}$ in Ar. Insets of (a) and (b) show the top views of samples annealed at $500^{\circ} \mathrm{C}$ for $0.5 \mathrm{~h}$ in air; insets of (c) and (d) show the high magnification of top views of (a) and (b); (e and f) corresponding element distribution of the oxide layer of the corresponding annealed (e) Fe and (f) Fe5Si alloy; ( $g$ and h) current-potential characteristics with chopped light of the annealed (g) Fe and (h) Fe5Si alloy. Inset graphs show magnified views of the 1.2-1.8 $\mathrm{V}_{\mathrm{RHE}}$ region for both spectra. Conditions: $1 \mathrm{M} \mathrm{KOH}$ solution ( $\mathrm{pH}: 13.6), 2 \mathrm{mV} \mathrm{s}^{-1}$ scan rate. Photocurrents are excited with $A M 1.5,100 \mathrm{~mW} \mathrm{~cm}^{-2}$ simulated sunlight.

$\mathrm{S} 2 \dagger)$. After formation, NFs were in dense arrays with sharp apexes. The NFs were of $\approx 500 \mathrm{~nm}$ for short annealing times (ESI, Fig. S3†), or up to approx. 1.5-2.5 $\mu \mathrm{m}$ long for longer annealing times (ESI, Fig. S2 $\dagger$ ). The flakes have typically a width of $200-500 \mathrm{~nm}$ at the base that tapers down to approximately $10 \mathrm{~nm}$ at the tips. The resulting nanorods (after Ar annealing) typically have a length of $\sim 2.5 \mu \mathrm{m}$ and a diameter of 100-200 $\mathrm{nm}$. A most significant difference between alloy and pure iron substrate is apparent from ion milled cross-section SEM images (Fig. 1c and d) and Auger electron spectroscopy line scans (Fig. 1e and f). The total thickness of the composite oxide layer on the Fe substrate is $\sim 2.5 \mu \mathrm{m}$, approximately five times thicker than that on the Si containing alloy $(\sim 500 \mathrm{~nm})$. (Please note that the top NR structure is not clearly visible in these cross-sections due to the nature of the ion milling treatment. Please see ESI, Fig. S4. $\dagger$ ) The elemental profile (Fig. 1f) shows that the FeSi alloy is strongly enriched with silicon at the metal-oxide interface. This is confirmed by GDOES (Fig. 2d) and ToF-SIMS depth profiles (Fig. 2e) where the elemental mapping (Fig. 2h) shows a significantly higher intensity of the signal corresponding to $\mathrm{Si}$ at the metal-hematite interface. The finding is in line with the general literature on the high temperature oxidation of $\mathrm{Fe}-\mathrm{Si}$ alloys that show a reduced oxidation rate relative to pure iron. ${ }^{8}$ Often this is ascribed to Si effects on the grain growth mechanism of iron oxide films.

Fig. $1 \mathrm{~g}$ and $\mathrm{h}$ show the photoelectrochemical water splitting behavior under simulated sunlight AM $1.5\left(100 \mathrm{~mW} \mathrm{~cm}^{-2}\right)$ conditions in $1 \mathrm{M} \mathrm{KOH}$ for pure Fe and the Fe5Si alloy. From the transient-photocurrent $v s$. potential curves for pure Fe, upon sweeping the potential from $0.5 \mathrm{~V}_{\mathrm{RHE}}$ to $1.8 \mathrm{~V}_{\mathrm{RHE}}$, the onset of water oxidation photocurrent is at $0.8 \mathrm{~V}_{\mathrm{RHE}}$, and the photocurrent increases to $0.4 \mathrm{~mA} \mathrm{~cm}^{-2}$ at $1.23 \mathrm{~V}_{\mathrm{RHE}}$. (A higher photocurrent is obtained for nanorod $\alpha-\mathrm{Fe}_{2} \mathrm{O}_{3}$ than for the air annealed NF sample (ESI, Fig. S5a†).) For the Fe5Si alloy, most remarkably a significant cathodic shift of the onset potential up to $0.4 \mathrm{~V}_{\mathrm{RHE}}$ can be observed. This value is very close to the flatband potential of $\alpha-\mathrm{Fe}_{2} \mathrm{O}_{3}\left(0.4 \mathrm{~V}_{\mathrm{RHE}}\right)$ and among the most negative values ever reported. ${ }^{9}$

It is noteworthy that for the Fe-Si alloy the suboxide layer thickness is varied; X-ray diffraction (XRD) results (Fig. 3 and $\mathrm{S} 6 \dagger$ ) show stronger hematite peaks for the $\mathrm{Fe}-\mathrm{Si}$ samples compared to the pure $\mathrm{Fe}$, which indicates a higher crystallinity of the iron oxide structures for the Si containing substrates. This may be in line with reports on minor Si concentrations that affect the crystallinity of $\mathrm{Fe}_{2} \mathrm{O}_{3} \cdot{ }^{1 f}$ The stronger (104) peak indicates that the $c$ axis of the hexagonal hematite unit cell is aligned perpendicular to the substrate or the basal planes are aligned perpendicular to the substrate. Supported by both the TEM analysis and the dark current onset potentials, and in line
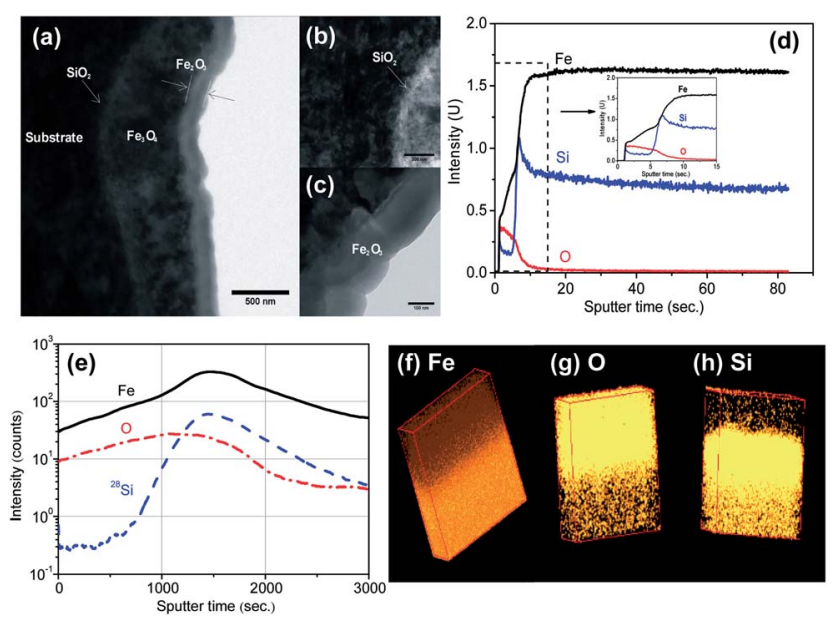

Fig. 2 (a-c) TEM image of the annealed Fe5Si alloy; (d) GDOES elemental depth profiles of an oxide layer of the Fe5Si alloy; (e) ToFSIMS depth profile for $\mathrm{Fe}, \mathrm{O}$, and $\mathrm{Si}$ species of the annealed Fe5Si alloy; (f-h) ToF-SIMS-EDS mapping of the Fe5Si alloy to show the distribution of $\mathrm{Fe}, \mathrm{O}$, and $\mathrm{Si}$, respectively. 


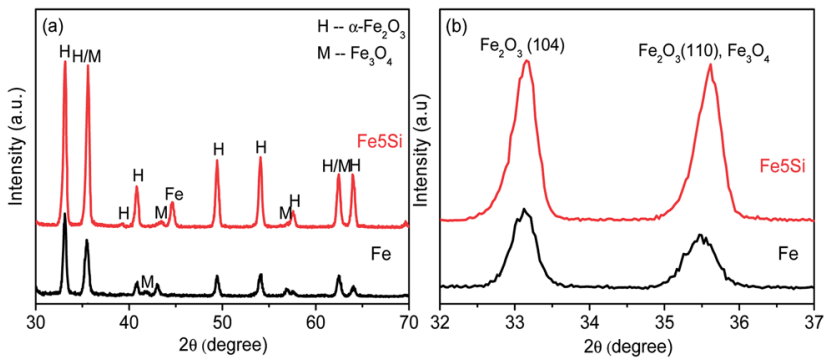

Fig. 3 (a) XRD patterns of the oxide films resulting from Fe and Fe5Si alloy annealed at $500{ }^{\circ} \mathrm{C}$ for $0.5 \mathrm{~h}$ in air $+600{ }^{\circ} \mathrm{C}$ for $1 \mathrm{~h}$ in $\mathrm{Ar}$ and (b) high magnifications between $2 \theta=32^{\circ}$ and $37^{\circ}$.

with the literature, ${ }^{1 f}$ the $\mathrm{SiO}_{2}$ layer can act as an amorphous buffer that reduces the interfacial strain between the $\mathrm{Fe}$ substrate and $\mathrm{Fe}_{3} \mathrm{O}_{4}-\mathrm{Fe}_{2} \mathrm{O}_{3}$ layers. The reduced interfacial strain would directly lead to better $\mathrm{Fe}_{3} \mathrm{O}_{4}-\mathrm{Fe}_{2} \mathrm{O}_{3}$ film organization at an atomic level, and is seen to directly affect crystallinity (ESI, Fig. S7 $\dagger$ ). Moreover, the better crystallinity could reduce the boundary defects, which also may explain the improvement of the photocurrent onset potential.

Fig. 4a shows the incident photocurrent conversion efficiencies (IPCEs) as a function of incident light wavelength for the Fe5Si alloy measured at various applied potentials. It is clear that the Fe5Si alloy leads to a significantly enhanced IPCE compared with pure $\mathrm{Fe}$ over the entire range from $300 \mathrm{~nm}$ to $550 \mathrm{~nm}$. A beneficial effect of the Ar annealing can also be evaluated from the transient photoresponse (Fig. 4b). From the figures one can see that the transient ratio values $\left(i_{\text {steady }} / i_{\text {initial }}\right)$ close to one have been obtained compared to those in air annealing in the range of 0.02-0.86 (ESI, Fig. S8 $\dagger$ ). In general, the photo transient shape reflects strongly on the density and energy of the trapping states. ${ }^{2 a, 10,11}$ In light of XRD results, this can be attributed to the increased crystalline order within the nanorod structure after Ar annealing.

In order to rule out the possibility that doping effects of the remaining $\mathrm{Si}$ in the $\mathrm{Fe}_{2} \mathrm{O}_{3}$ structure are the source of the shift in the onset potential, one may consider the following: according to earlier work, ${ }^{12}$ at least 1 at $\%$ Si needs to be present to clearly show a beneficial doping effect in hematite. However, if ToF-SIMS results (ESI, Fig. S9†) are quantified, only a Si concentration $<0.2$
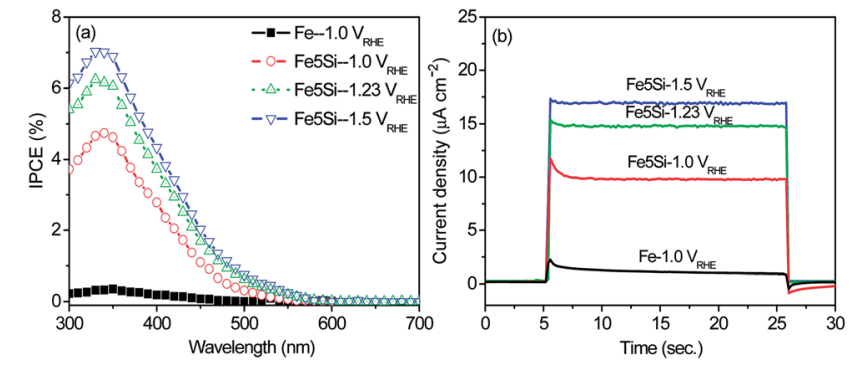

Fig. 4 (a) The incident photon conversion efficiency (IPCE) and (b) photocurrent at $360 \mathrm{~nm}$ at applied potentials (1.0 $\mathrm{V}_{\mathrm{RHE}}, 1.23 \mathrm{~V}_{\mathrm{RHE}}$, and $1.5 \mathrm{~V}_{\mathrm{RHE}}$ ) in a $1 \mathrm{M} \mathrm{KOH}$ solution of the Fe5Si alloy annealed at $500^{\circ} \mathrm{C}$ for $0.5 \mathrm{~h}$ in air $+600{ }^{\circ} \mathrm{C}$ for $1 \mathrm{~h}$ in $\mathrm{Ar}$. at $\%$ in the oxide layer is at the maximum present. Therefore, the results presented here strongly suggest that the beneficial effect is due to the impact of crystallography of the iron oxide films and the strongly reduced $\mathrm{Fe}_{1-x} \mathrm{O}$ layer for the Fe5Si alloy.

\section{Conclusions}

In summary, in this work we grew oxide nanostructures by conventional thermal oxidation of Fe and FeSi alloys. A clearly improved water splitting performance is obtained for the $\mathrm{Si}$ containing alloy. Particularly, a remarkable cathodic shift of the onset potential up to $0.6 \mathrm{~V}_{\mathrm{RHE}}$ is observed for the Fe5Si alloy. This is one of the most negative onset potentials reported for hematite photoanode devices and is achieved without the use of other catalysts. We ascribe this strong beneficial effect to an accumulation of $\mathrm{SiO}_{2}$ at the metal-oxide interface this Si-enriched layer hampers the formation of suboxides, namely $\mathrm{Fe}_{3} \mathrm{O}_{4}$, which is particularly detrimental to the performance of a hematite based water splitting anode and an increased crystallinity of the $\mathrm{Fe}_{2} \mathrm{O}_{3}$ layer among the layers formed on the Fe-Si alloy.

\section{Acknowledgements}

We would like to acknowledge Dr Natalie Kömpel (Neue Materialien Fürch GmbH, NMF) for GDOES measurements. We thank DFG and the DFG cluster of excellence "Engineering of Advanced Materials" (EAM) for the financial support.

\section{Notes and references}

1 (a) A. Duret and M. Grätzel, J. Phys. Chem. B, 2005, 109, 17184; (b) J. Brillet, M. Grätzel and K. Sivula, Nano Lett., 2010, 10, 4155; (c) K. Sivula, F. L. Formal and M. Grätzel, ChemSusChem, 2011, 4, 432; (d) K. Sivula, R. Zboril, F. L. Formal, R. Robert, A. Weiden kaff, J. Tucek, J. Frydrych and M. Grätzel, J. Am. Chem. Soc., 2010, 132, 7436; (e) S. D. Tilley, M. Cornuz, K. Sivula and M. Grätzel, Angew. Chem., Int. Ed., 2010, 49, 6405; (f) F. Le Formal, M. Grätzel and K. Sivula, Adv. Funct. Mater., 2010, 20, 1099; (g) L. Wang, C.-Y. Lee and P. Schmuki, J. Mater. Chem. A, 2013, 1, 212; (h) L. Wang, A. Palacios-Padrós, R. Kirchgeorg, A. Tighineanu and P. Schmuki, ChemSusChem, 2014, 7, 421.

2 (a) M. Frites and S. U. M. Khan, ECS Trans., 2009, 19, 137; (b) H. G. Kim, P. H. Borse, J. S. Jang, C. W. Ahn, E. D. Jeong and J. S. Lee, Adv. Mater., 2011, 23, 2088; (c) C.-Y. Lee, L. Wang, Y. Kado, S. Killian and P. Schmuki, ChemSusChem, 2014, 7, 934.

3 (a) M. P. Dareedwards, J. B. Goodenough, A. Hamnett and P. R. Trevellick, J. Chem. Soc., Faraday Trans., 1983, 79, 2027; (b) J. B. Goodenough, Prog. Solid State Chem., 1971, 5, 145; (c) J. H. Kennedy and J. K. W. Frese, J. Electrochem. Soc., 1978, 125, 709.

4 (a) P. Hiralal, S. Saremi-Yarahmadi, B. C. Bayer, H. Wang, S. Hofmann, K. G. Upul Wijayantha and G. A. Amaratunga, Sol. Energy Mater. Sol. Cells, 2011, 95, 1819; (b) T. Vincent, 
M. Gross, H. Dotan and A. Rothschild, Int. J. Hydrogen Energy, 2012, 37, 8102; (c) L. Wang, C.-Y. Lee, A. Mazare, K. Lee, J. Müller, E. Spiecker and P. Schmuki, Chem. - Eur. J., 2014, 20, 77.

5 (a) X. Wen, S. Wang, Y. Ding, Z. L. Wang and S. Yang, J. Phys. Chem. B, 2005, 109, 215; (b) A. G. Nasibulin, S. Rackauskas, H. Jiang, Y. Tian, P. R. Mudimela, S. D. Shandakov, L. I. Nasibulina, J. Sainio and E. I. Kauppinen, Nano Res., 2009, 2, 373.

6 (a) Q. Yang, H. Kukino and H. J. Tatsuoka, Nanosci. Nanotechnol., 2010, 10, 7795; (b) X. Su, C. Yu and C. Qiang, Appl. Surf. Sci., 2011, 257, 9014; (c) B. D. Chernomordik, H. B. Russell, U. Cvelbar, J. B. Jasinski, V. Kumar, T. Deutsch and M. K. Sunkara, Nanotechnology, 2012, 23, 194009.

7 (a) N. Beermann, L. Vayssieres, S. E. Lindquist and A. Hagfeldt, J. Electrochem. Soc., 2000, 147, 2456; (b) Z. Chen, U. Cvelbar, M. Mozetic, J. He and M. K. Sunkara, Chem. Mater., 2008, 20, 3224; (c) U. Bjorksten, J. Moser and M. Grätzel, Chem. Mater., 1994, 6, 858.
8 (a) I. Svedung and N. G. Vannerberg, Corros. Sci., 1974, 14, 391; (b) T. Adachi and G. H. Meier, Oxid. Met., 1987, 27, 347; (c) J. Kucera and M. Hajduga, High temperature and long time oxidation of iron and steels, Wydawnictwo PL Filia W, Bielsku-Bialej, 1998, vol. 15; (d) T. Ban, K. Bohnenkamp and H. J. Engell, Corros. Sci., 1979, 19, 291; (e) A. R. Lashin, O. Schneeweiss and Y. Houbaert, Corros. Sci., 2008, 50, 2580.

9 M. T. Mayer, C. Du and D. Wang, J. Am. Chem. Soc., 2012, 134, 12406.

10 (a) N. Birks, G. H. Meier and F. S. Pettit, Introduction to the high temperature oxidation of metals, Cambridge University Press, Cambridge, New York, 2nd edn, 2006; (b) M. A. Lukowski and S. Jin, J. Phys. Chem. C, 2011, 115, 12388. 11 P. Iwanski, J. Curran, W. Gissler and R. Memming, J. Electrochem. Soc., 1981, 128, 2128.

12 (a) J. H. Kennedy, M. Anderman and R. Shinar, J. Electrochem. Soc., 1981, 128, 2371; (b) J. H. Kennedy, R. Shinar and J. P. Ziegler, J. Electrochem. Soc., 1981, 127, 2307; (c) C.-Y. Lee, L. Wang, Y. Kado, R. Kirchgeorg and P. Schmuki, Electrochem. Commun., 2013, 34, 308. 